\title{
Dissertações Não-Acadêmicas em Mestrados Profissionais: Isso é Possível?
}

Pedro Lincoln Mattos

\section{RESUMO}

Este trabalho trata de um aspecto particular da questão dos mestrados profissionais em administração: seu trabalho final, ou dissertação. Na Portaria n. 47, de 17/10/95, a CAPES incentiva e regula a matéria. Defende-se a posição de que, assim como as boas dissertações acadêmicas, as dissertações em mestrados profissionais: a) cabem no conceito de ciência, guardada a condição essencial desta, e, por isso, a pós-graduação stricto sensu é seu locus adequado; b) têm características próprias. O texto desenvolve-se em quatro partes. Na primeira se trata da oportunidade da pergunta-título e seu caráter problemático. Na segunda, se faz uma análise crítica das dissertações no meio acadêmico, com especialidade o da administração. $\mathrm{Na}$ terceira, mais longa, se discute a questão central do que seja um trabalho científico. Na quarta, se definem características das dissertações de mestrados profissionais em administração, e se exploram alternativas de estratégia e estrutura para elas.

Palavras-chaves: dissertações-metodologia, mestrados profissionais em administração, trabalho científico.

\section{ABSTRACT}

This article deals with a particular aspect of the question of master courses for nonacademic professionals in administration: the dissertation, their final work. CAPES (Brazil's federal agency for development of higher education personnel), in its Governmental Order (Portaria n. 47, of 17/10/95), stimulates and regulates the matter. The author stands that this kind of dissertation, like good academic dissertations: a) fits the concept of science, as long as the essencial condition of it is kept. Thus, graduate studies are its adequate locus; b) has its own peculiarities. The text comprises four parts. The first deals with the opportunity of the question-title and its problematic feature. In the second, a critical analysis of dissertations in academic milieu is made. In the third, the longest, the central question of what is a scientific work is discussed. In the fourth, some distinguishing traits of dissertations of master courses for professionals in administration are defined and some options of strategy and structure for them are explored.

Key words: dissertation-methodology, master courses for administration professionals, scientific work. 


\section{INTRODUÇÃO}

Este artigo trata de um aspecto particular da questão dos mestrados profissionais em administração. Entendem-se como mestrados profissionais aqueles que são dirigidos para clientela dos meios profissionais, não acadêmicos ou universitários, visando a qualificar pessoas daqueles meios em nível de pós graduação stricto sensu. Tem-se como suposto: a) que lhes seja institucionalmente permitido ter dissertações defendidas perante banca, não apenas trabalhos monográficos menores; b) que a qualificação de "científico" como critério é denominador comum para a discussão. As perguntas são progressivamente postas: as dissertações de mestrados profissionais devem seguir o figurino metodológico praticado na academia? Como ele, afinal, não é generalizado nem rígido, até onde seria permitido ao desenho de uma dissertação em tais mestrados afastar-se das práticas acadêmicas atuais? Enfim, são possíveis, nos limites do trabalho científico, dissertações "não-acadêmicas"?

Defende-se a posição de que, assim como as boas dissertações acadêmicas, as dissertações em mestrados profissionais: a) cabem no conceito de ciência, guardada a condição essencial desta, e, por isso, a pós-graduação, stricto sensu é seu locus adequado; b) têm características próprias. Não faz parte do objeto do estudo, mas está em sua motivação, a idéia de que as dissertações, trabalhando problemas reais da organização, constituem o centro de gravidade dos mestrados profissionais. Também não está no escopo do estudo discutir se outras formas de trabalho de conclusão do mestrado, de natureza puramente técnica, como o admite a CAPES, devam ser aceitas na pós-graduação stricto sensu.

O texto desenvolve-se em quatro partes. Na primeira se trata da oportunidade da pergunta-título e seu caráter problemático. Na segunda, se faz uma análise crítica das dissertações no meio acadêmico, com especialidade o da administração. $\mathrm{Na}$ terceira, mais longa, se discute a questão central do que seja trabalho científico. $\mathrm{Na}$ quarta, se definem características das dissertações de mestrados profissionais em administração, e se exploram alternativas de estratégia e estrutura para elas.

\section{Por que a Pergunta?}

Apesar de poucos, os mestrados profissionais em administração estão em debate. A expansão dos cursos de especialização, tornados mercadologicamente híbridos pela sigla "MBA", coloca à academia, com seus tradicionais cursos de mestrado em administração, a realidade da demanda profissional a cujo atendi- 
mento ela nunca negou pretensões. No mínimo, a situação gera um "efeito espelho". A academia em administração, que já discute o assunto nos ENANPADs, pelo menos desde 1993, deve confrontar-se consigo mesma quanto a esse procedimento tradicional e básico que é a dissertação de mestrado.

Atinge a área de administração a preocupação do Governo e meios científicos representados junto a ele, relativa a mestrados profissionais, expressa em política oficial da CAPES, cuja Presidência transformou em Portaria n. 47, de 17 de outubro de 1995, a Resolução n. 01/95 de seu Conselho Superior, e que tem base no documento "Programa de flexibilização do modelo de pós-graduação, senso estrito, em nível de mestrado", que traz anexo. Diz a CAPES $(1995$, p. 4) que a qualificação acadêmico-científica, ao contrário do que se pensava na década de 60, quando se instituiu a pós-graduação no Brasil, "não é mais suficiente para também assegurar a formação de pessoal de alta qualificação para atuar nas áreas profissionais, nos institutos tecnológicos e nos laboratórios industriais".

A Resolução n. 01/95 estabelece condicionantes e requisitos aos mestrados profissionais, relativos às instituições que os promovem e ao corpo docente por eles responsável, "para assegurar níveis de qualidade comparáveis aos vigentes no sistema de pós-graduação e consistentes com a especificidade dos cursos" (CAPES, 1995, p. 1). O que é, no entanto, a qualidade que se quer preservar? Será ela garantida pelos elementos formais (titulação do corpo docente, experiência da instituição e conceito avaliativo favorável de seus cursos, participação de profissionais da área, inquestionavelmente qualificados, e outros)? Vista como maximização da adequação aos fins e à natureza do programa, a questão da qualidade conduz à da especificidade e abre campo à reflexão sobre as diferenças substantivas de pesquisa e conhecimento, determinadas pela démarche, interesse e utilidade que os inspira. Nesse sentido, deixa dúvidas mais que definição de rumo a afirmação do documento oficial de que "o curso deverá articular as atividades de ensino com as aplicações de pesquisas, em termos coerentes com seu objetivo" (CAPES, 1995, p.1, grifo nosso). Teria ele querido referir-se à pesquisa aplicada? Ou estaria afirmando que dos mestrados profissionais mais se espera aplicação que produção de pesquisa? Ou não reconhece foro próprio à pesquisa profissional?

Diz o item 5 da Resolução que é preciso flexibilizar as formas de trabalho final, citando entre exemplos, a própria dissertação. Em que se justificaria, contudo, do ponto de vista científico, sua diferenciação em relação às formas da pós-graduação tradicional?

Enfim, considerando que mestrados profissionais são produzidos pela própria academia, é preciso, a quem quer que esteja seriamente interessado em suas dissertações, considerar-lhes "o fator hereditário" e "o genes de mutação" desejado. 


\section{Dissertaçóes no Mundo da Comunidade Académica}

\section{Em Nome do Método}

Nas histórias de dissertações e teses, pela academia afora, quanta coisa terrível se tem feito em nome da formalização e do método! Quantos mestres e doutores se sentiram invadidos, após concluírem, com aparente sucesso, seus trabalhos de conclusão de curso, por um sentimento de aversão àquela experiência de vida! Há os que suportam certa vinculação, na seqüência de suas carreiras, ao tema da dissertação, apenas como um espólio que sobrou daqueles anos de guerra e aflição. A questão da metodologia científica é uma das fontes de poder dos orientadores sobre os orientandos; há casos de relacionamento difícil; há recém-doutores e mestres que se imaginam saídos de uma espécie de câmara de tortura acadêmica. A sensação de alívio supera a de satisfação. Talvez não tenham mais uma lembrança clara de que a maior parte do seu trabalho, de suas inseguranças e agruras se dava em torno da armação e do cumprimento da metodologia, das questões de forma e apresentação do argumento. Afinal, em nome do método!

Ora, no quadro de desenvolvimento atual das ciências quanto mais consolidada ela é - tome-se o caso da física e da biologia - mais abertos estão seus setores de ponta às interfaces com outras ciências (outros métodos), às fronteiras do conhecimento, a outras tradições de saber. A tendência se expande ao grande público, embalada pelo misticismo contemporâneo e se generaliza a convicção de que há outras maneiras válidas de conhecer. O método, de qualquer forma, particularizado por escolas e comunidades científicas, continua apanágio social dos ambientes acadêmicos.

\section{Afinal, que é Dissertação?}

Que é, do ponto de vista sociológico, dissertação? Um rito de iniciação ou de promoção na hierarquia do grupo (comunidade acadêmica), tal como ocorre em qualquer outro, de tribos aborígines a clubes esportivos. Em essência, é preciso cumprir uma tarefa praticada dentro dele - no caso da academia, usualmente, escrever um texto - e satisfazer a certas exigências na maneira de fazê-lo, sem que haja também, para tal, estrita padronização. Para o mestrado, a prática da dissertação inclui diversos tipos de texto, indo de formas muito próximas das dissertações de doutorado até levantamentos bibliográficos (aceitáveis?).

Lamentavelmente, a descrição sociológica, voltada para a apresentação externa desse fenômeno, expressa também grandemente a motivação dos que conduzem a 
produção de dissertações, revelando um nível muito modesto de criação do conteúdo. A competência formal prevalece sobre a dinâmica de descoberta da realidade, e a metodologia, deixando de ser um simples apoio ao processo criativo, começa a ser, por sua qualidade de objetivação, o centro de gravidade tanto para o desenvolvimento do trabalho de dissertação como para seu julgamento social (será exagero falar da "tirania" do método?).

Na verdade, a formalização que atormenta mestrandos e doutorandos é função da dimensão social do rito dissertatório. Precisa acontecer o reconhecimento social por um determinado grupo, assaz fechado. E distorções acontecem porque se credita inteiramente à formalização do método - na explicitação da estrutura da dissertação, de seus limites, dos procedimentos de coleta e tratamento quantitativo de dados - a sua integridade, e se atribui ao método, tout court, a tão aspirada objetividade do conhecimento.

O que acontecerá se, e quando, submetermos pessoas de outro meio profissional, socialmente pertencentes a organizações e culturas empresariais, ao ritual de iniciação e promoção grupal, praticados com mestrandos em meios acadêmicos? Para grande parte dos casos, o prestígio do conhecimento tido como científico, ou do título, falará mais alto e as pessoas procurarão adaptar-se. Mas, provavelmente, haverá dificuldades especiais, e muitas delas não concluirão a dissertação, levando para casa a culpa, uma sensação de incapacidade. E a empresa? Se o curso corre, afinal, por conta do Governo e sua função social, a empresa não se importará muito em não receber, com a dissertação, produto diretamente aplicável. Se, por custear alto o treinamento, o levar a sério, ela sentir-se-á frustrada, mesmo sem ousar por em questão o mérito e o método acadêmicos. Pensará apenas em termos de "MBA's" (versão brasileira), cursos de especialização e treinamentos intensivos e de curta duração, que continuarão sendo a grande alternativa, em detrimento da produção de um conhecimento original e de alcance estratégico. Há até o caso em que será o próprio pós-graduando que se afastará interiormente da empresa, passando a alimentar dentro de si a idéia de um dia poder ir para a universidade, talvez até fascinado pela descoberta de seu próprio potencial acadêmico. Em muito poucas situações se denunciará certo "estelionato intelectual" com perdão pela força de expressão - praticado pela academia neste crescente mercado do conhecimento em administração.

É de colocar-se o desafio: ou entendemos mais profundamente o sentido e as funções da formalização e do método científico, para viabilizar-lhe utilização seletiva fora de seu berço cultural, a academia, ou acabamos por afirmar o virtual monopólio desta sobre a ciência e, pretensiosamente, a aplicabilidade direta de seu produto na vida das organizações públicas e privadas, negando sentido específico à pós-graduação stricto sensu para meios profissionais.

Contudo, se distinguimos, da qualidade substantiva do conhecimento, o fenômeno social de sua prática institucionalizada e se nos dermos conta do avanço 
feito, nas últimas décadas, pela filosofia do conhecimento, sociologia e história da ciência, abrir-se-ão à frente interessantes oportunidades de inovação metodológica e solução para o problema.

\section{Que é Trabalho Científico?}

\section{Situando a Questão}

Como julgamos merecer o ambicionado diferencial, o status de conhecimento científico? Isso passa de forma meio inconsciente no dia-a-dia das atividades universitárias e profissionais de produção de conhecimento, e com isso têm que ver as dissertações de mestrado. Freqüentemente, o conceito usado é mais confuso e elementar do que se pensa. "Científico", para uns, é o que usa processos mais sofisticados, reconhecidos, exatos, além do que as pessoas sabem pela razão natural e o senso comum. Para outros, (ainda!) é, simplesmente, sinônimo de conhecimento verdadeiro.

Uma das discussões mais provocadoras e cruciais da filosofia da ciência é a do critério de cientificidade, o que distingue a ciência da não-ciência. Assim o é pelo fato básico da divergência entre as escolas nesse ponto, não sendo aceitável a afirmação unilateral, por uma delas, de seu critério, usando argumentação circular (com o próprio critério). Por outro lado, o postulado da ciência é o questionamento, e este não pode negar a própria condição de questionar ("condição performativa de Apel"), erro em que incorreria a metodologia que se declarasse acima de questionamento (Apel apud Demo, 1996, p. 22). A discussão toca "o fundo do poço" da certeza do conhecimento humano, e não está condenada ao relativismo. Assistimos nos últimos 50 anos a uma ruptura epistemológica que nos reaproximou do senso comum e que nos levou da ciência moderna à pós-moderna (Santos, 1989). Hoje ela inscreve a ciência num quadro metodologicamente pluralista e abre novas perspectivas de legitimidade na criação de conhecimento no mundo da prática (Shön, 1983). Tem impacto direto na concepção de trabalhos de conclusão de mestrados profissionais afirmar que a cientificidade é, antes de tudo, uma condição social, associada ao processo de comunicação no esforço humano pelo conhecimento, não um procedimento com valor em si, algo como "uma chave de acesso à realidade". Os parágrafos seguintes introduzem brevemente essa idéia.

\section{A Crise do Conceito de Clência}

Sempre houve diversidade de concepções epistemológicas, mas o positivismo, em suas variedades e versões, foi o herdeiro da vertiginosa expansão das ciências ditas "naturais" e suas aplicações tecnológicas, do século XVIII às primeiras 
décadas do século XX, e pareceu que a metodologia da ciência recomeçava a partir dele. Científico só o verificável no mundo dos fatos; o dado testado é fiel à realidade. Foi também da crítica ao empirismo positivista (Popper, 1965, 1972) e seu método que evoluiu a concepção atual sobre ciência. O desmonte da ingenuidade (ou pretensão?) positivista, especialmente em ciências humanas (Lincoln e Guba, 1985), veio quase simultaneamente pela epistemologia, pela sociologia da ciência e até pela física moderna.

Simplesmente não é mais possível hoje sustentar a unicidade do método, a concepção nomotética (há uma ordem estável no mundo, cujas "leis" a ciência busca descobrir) e transcultural da ciência (Lyotard, 1984). Desde Kant, a epistemologia é um campo de discussão em que avulta a convicção de que não há apreensão direta e imediata da realidade (tal como ela é), de que as ciências do homem, entre as quais a administração deveria ser classificada, não propiciam a mesma distância (epistemológica) entre sujeito e objeto, que nas ciências ditas "da natureza" (ainda quando têm o homem como objeto no universo). Ou seja, o envolvimento é um dado definitivo, não pode ser resolvido pelos mesmos procedimentos metodológicos daquelas ciências (Barchelard, 1972). E foi-se além. Hoje já é aceito que, se os homens pensam culturalmente diferente, toda a ciência (incluindo as ciências naturais) tem uma marca cultural intrínseca, definidora (Geertz, 1983).

Desde meados deste século, apresentou-se com Popper solução para o problema lógico do método indutivo, em que se afirma a iniciativa (e quase primazia) da hipótese e em que se reposiciona a empiria no método da ciência natural. Veio a derrocada do empirismo e a conseqüente (terrível!) queda da verificação como critério de verdade. A experiência não confirma a teoria. Por mais "testado", por mais eficaz, todo conhecimento geral ou interpretativo é previsão e permanece conjectural. No máximo - se houvesse consenso entre os cientistas - seria o mais bem justificado do momento. Distanciou-se de nós o sonho do conhecimento definitivo ou linearmente cumulativo da realidade. A rigor, toda observação é seletiva (Habermas, 1982) e a interpretação não vem depois do dado, "que só fala pela boca de uma teoria" (Demo, 1989, p.133), embora o dado interpretado passe a ter fecundidade interpretativa própria.

Chegou, assim, aos meios científicos a convicção da objetividade impossível, superado embora o relativismo grosseiro e autocontraditório. Sabemos que sabemos algo (considerado muito, para nós) da realidade, embora não saibamos quanto, e tenhamos hoje certeza de que não há correspondência exata entre nossas categorias mentais e as da realidade (Habermas apud Demo, 1989). Objetividade propriamente dita é impossível, não apenas porque os valores - até o da racionalidade (Popper, 1974) que não se justifica a si mesma sem um raciocínio tautológico - estão por trás dos estudos científicos (Bredo e Feinberg, 1982); não 
apenas porque a ideologia - entendida largamente como o condicionamento social do poder, dos compromissos e interesses - é universal, inconsciente, inevitável, mesmo na ciência (Barnes, 1977); mas porque hoje se voltou à consciência de que todo conhecimento, mesmo sobre o objeto, é, definitivamente, do sujeito, e não há acesso direto à realidade (Habermas apud Demo, 1989).

De certa forma ao encontro disso vem o avanço da física. Como já deixara claro a própria física newtoniana, toda observação é relativa à posição do observador, a qual é móvel (Einstein) e as condições do experimento sempre alteram a realidade (Eisenberg). Para a física quântica, no entanto, em nível de partículas subatômicas, tudo é um conjunto só, de que rigorosamente fazemos parte e não somos centro de referência, exceto na perspectiva de nosso próprio conhecimento. Assim, o mundo não "está" diante de nós como objeto de observação (Bohr, Gregory, Pagels). Como fica então "a verdade" que a ciência "descobre"?

As pesquisas de história das ciências física e química, aquelas consideradas mais maduras, que o nome de Thomas Kuhn veio a simbolizar após quase meio século de contribuições antes dele, levaram a entender melhor a natureza não cumulativa mas circunstancial do conhecimento científico. O impacto dessa constatação provocou crise no interior do paradigma (a obra de Kuhn descrevia a formação e ruptura de paradigmas...), refletida entre os filósofos da ciência, já na década de 60 (Lakatos e Musgrave, 1970).

Os estudos críticos de sociologia do conhecimento abriram espaço à hermenêutica e à fenomenologia, descreveram a "construção social da realidade" (Berger e Luckmann), e, voltando-se depois para os laboratórios e academias, rastrearam os caminhos decisórios da produção científica (Knorr-Cetina, 1981) e desmitificaram a condição humana e social dos cientistas e as "caixas-pretas" em que se tranforma sua produção (Latour, 1987).

O neomarxismo da Escola de Frankfurt reinterpretou o fenômeno da alienação, firmou nos meios acadêmicos sua tese de que é legítimo estudar e pesquisar a partir de uma posição prática e para ela, o que não contraria a objetividade - dado que esta e a neutralidade ideológica são mitos (Gadamer, 1975). A condição é apenas de que a opção prática e mesmo ideológica não seja escamoteada e se persiga a objetivação metodológica no tratamento do assunto, como completa um prócer de tradicional escola liberal (Dahrendorf, 1974).

Os estudos psicanalíticos que tinham na "hipótese não-testável" do inconsciente uma surpreendente origem explicativa do comportamento humano acabaram por criar um campo próprio, paralelo, percorrido por espíritos críticos, inteligentes e respeitados, cindindo ainda mais o monolitismo dos métodos científicos tradicionais. Em outros campos do saber demonstrou-se a distância entre linguagem e 
realidade interior humana, bem como a complexidade do símbolo. Desfez-se, dessa forma, totalmente, o mito da mensuração como forma segura de captar o que se passa dentro do homem.

É de admirar-se que, nos meios acadêmicos da administração no Brasil, ainda seja dominante a abordagem metodológica empírico-positivista (Martins, 1993) que, de há muito, começou a conceder o pressuposto da cientificidade a outras opções de método, especialmente nas ciências do homem e da sociedade!

\section{O Critério da Cientificidade}

Em conseqüência de toda essa evolução, a discussão da cientificidade passou a destacar critérios extrínsecos às suas conclusões e mais relativos à especificidade argumentativa do discurso, ela própria envolvida por um ambíguo consenso médio dos julgamentos especializados sobre ele ("intersubjetividade"). Não se caindo no circumlóquio de que "ciência é o que os cientistas fazem", se deslocou para a prática científica o eixo da discussão dos critérios de cientificidade. Lá se situam os critérios intrínsecos e extrínsecos do trabalho que se pretende científico.

De Popper a Habermas em nível teórico e, em nível prático, por toda a extensão do pluralismo atual dos meios científicos, resta de comum que a ciência é um discurso crítico, movido pela fé na possibilidade humana do acerto. Crítico, no sentido de feito com critério crítico sobre qualquer conhecimento anterior, e no sentido de exposto à crítica. Na linha dos critérios intrínsecos ao trabalho científico, as grandes condições para isso são de que o discurso seja claro em seu objeto, consistente em seu argumento e, principalmente, transparente, "aberto" em seu método, que diga como procedeu a caminho de seus resultados e conclusões, justamente para que outros possam também percorrer tal caminho e discuti-lo, avançando assim o conhecimento comum através da crítica. Justamente nisto se configura o critério extrínseco da cientificidade: o julgamento social desta qualidade formal e estrutural do discurso e o reconhecimento social da relevância do conhecimento. Diante de um trabalho que se pretende científico, apresentado a uma banca de mestrado ou doutorado, não cabe julgamento final do mérito das conclusões em si mesmas mas da forma como se chegou a elas, sua sustentação por quem as apresenta, e da relevância da contribuição para o meio. Isso implica, pois, em falar de critério intrínseco e critério extrínseco.

Na análise da ciência que Popper faz, a partir da postura das ciências naturais, o que distingue a ciência da não-ciência é a falseabilidade ou "refutabilidade" (Magee, 1975). Para ele, a ciência sempre estará afirmando alguma coisa a respeito do mundo (hipótese) e deverá criar uma forma de teste negativo dela, pela 
observação. Ao contestar os positivistas, no entanto, ele admite significado e consistência no discurso crítico (sic!) sem testes pela observação, como é o caso, por exemplo, de toda a metafísica, e admite sua legitimidade nos meios científicos. Isso mostra que, em Popper, há apenas um uso restrito do termo ("científico") e amplo do conceito. Até porque as teorias "não-científicas" não devem ser abandonadas inteiramente: elas são base para outras hipóteses, hoje ou no futuro. Fornecer elementos para a contestação é o critério fundamental do trabalho científico, como o expressa Eco (1989). Esta é a posição que, no contexto das ciências humanas, Habermas chama de "discutibilidade" (Demo, 1996, p. 21). "Somente pode ser científico o que for discutível. A ciência tem compromisso ineludível de ser crítica e criativa" (Habermas apud Demo, 1996, p.21). Esta é condição necessária e bastante como critério intrínseco ao discurso.

\section{Relevância do Problema: Prática e Teoria}

Definida a marca social da ciência, cabe vincular a ela o conceito de relevância do problema em estudo. A relevância se coloca em nome da ética e, no caso do conhecimento em administração, tem na prática sua referência original.

Primeiro, relevância é essencial em nome da ética. A ciência - tradição - trabalha com patrimônio rigorosamente coletivo e público, construído ao longo de séculos. Além disso, o compromisso inovador do conhecimento é a grande lição da história da ciência e da filosofia. Trabalhos autodeletantes ou de certa "esquizofrenia acadêmica" constituem momentos de alienação nessa história. Assim, o que não consegue mostrar que contribui para a sociedade, para aquela história e aquele patrimônio, não deve ser julgado digno deles.

Segundo, no caso de campos de estudo como a administração, a prática é condição da relevância porque gera a fecundidade da própria produção científica. Tem chances de trazer algo novo para o conhecimento, o problema estudado de forma próxima e atenta às situações reais da ação, da prática, do contexto e do momento. A prática não pode ser vista como "campo de aplicação" da teoria mas, antes de tudo, como situação de criação dela.

Há, na história das ciências humanas uma longa tradição de reconhecimento da unidade entre ação e pensamento, sendo este, em sua totalidade, expressão das condições de situação do homem, a despeito da consciência de originalidade pura do ato de pensamento e integridade absoluta de seu objeto. Da sociologia de Marx à psicologia de Vigotsky, afirmando a causalidade maior das relações econômicas e sociais, da epistemologia genética e dialógica de Piaget à pedagógica de Paulo Freire, todas orientadas para a recuperação do homem a partir do reconhecimento daquela condição maior da mente humana, da descrição, por alguns gestaltistas, 
do ato de apreensão ao interacionismo simbólico de Blumer, inspirado em Mead, da pedagogia da ação, de Dewey, à reflexão-na-ação, de Shön, o pensamento humano é explicado a partir do homem em situação, espaço-tempo e relação. Hoje, nos meios intelectuais e na própria evolução da cultura, é afirmada cada vez mais "uma inversão entre teoria e prática" (Habermas, 1990, p. 15).

Enfim, a dimensão social da ciência implica o julgamento da relevância para o fim prático do esforço despendido, que nunca é individual. Quem representa este esforço, o "patrocinador do mestrado", que participou de seu custeio, tem direito àquele julgamento.

\section{Cientificidade e Dissertações em Mestrados Profissionais}

Do que precede, e como base da diferenciação de dissertações não-acadêmicas em mestrados profissionais, cabe sintetizar: a) não é possível afirmar mais a unicidade do método científico, que, de qualquer forma, não repousa na verificação; b) nos meios que a cultivam, a ciência está mais freqüentemente como simples fenômeno de especialização social: não é apanágio da academia; c) o conhecimento crítico é a característica maior da cientificidade, devendo todo o arsenal metodológico, ainda o de testes empíricos, ser tratado como opções preferenciais de culturas acadêmico-científicas; conhecimento crítico é aquele que, incluindo uma dimensão reflexa sobre o método, supõe a necessidade radical de justificativa e se faz em condições de ser reconhecido no seu processo; d) a cientificidade deve ser conceituada como qualidade social do conhecimento, primeiro porque sua própria qualidade metodológica formal deve ser socialmente reconhecida, e, segundo, porque o trabalho científico tem de ser socialmente aceito como relevante. Queira-se ou não, resta que a ciência é fenômeno social e patrimônio coletivo.

Afinal, o julgamento da própria cientificidade de dissertações de mestrado profissional - se são aceitas ou não pela "comunidade" científica, as aspas indicando que, na verdade, não há comunidade quanto ao método - deve passar pela discussão da academia. Esta, no entanto, precisa fazer tal julgamento nos limites do que for atribuível às características de conhecimento crítico. Ela já não pode, portanto, em função do que se argumentou acima, considerar a cientificidade impossível de ser achada naquelas dissertações, sem confessar sua incapacidade de diálogo e contribuição para o conhecimento no mundo profissional, no caso, da administração. E, se a academia se supõe credenciada, pela natureza do que produz, a falar ao mundo da empresa e da produção, é forçoso que aceite discutir formas alternativas de produzir conhecimento crítico com finalidades práticas que não o atendimento de suas próprias preocupações e polêmicas internas, ou a manutenção de suas tradições e instituições. 


\section{No Coração da Contribuição Acadêmica para a Administração: a Análise Conceitual}

Predominam como processos básicos de elaboração de soluções na prática da administração o conhecimento genericamente dito intuitivo e a reprodução da experiência acumulada. A convicção, elemento cognitivo-emotivo, e o acervo de experiência própria ou alheia interpretadas, elemento cognitivo, são os principais critérios para o julgamento prévio da conveniência e eficácia. Usam-se as lógicas indutiva e dedutiva e o processo comparativo, próprios do senso comum. Elementos emocionais costumam precipitar a ação, mesmo aquelas que incluem prática reflexiva e tempo para amadurecimento.

Nas organizações com melhor estrutura e cultura de planejamento, fazem-se planos, projetos e relatórios, em que surgem, explicitamente, conceitos e definições, ou se importam, via consultores e literatura de divulgação, idéias, especulativas ou práticas, e esquemas conceituais elaborados. Qual é o critério de julgamento e aceitação/rejeição deles? Novamente o feeling da experiência? Seu charme de nouvelle vague? A autoridade de quem os emite? O apelo da solução, ainda não tentada, para a frustração do problema não resolvido? A "prudência" e credibilidade das avaliações numéricas? Provavelmente um misto dessas coisas, realizadas conforme a estrutura de poder na organização.

Raramente se faz, no planejamento empresarial, seja ele institucional ou informal, a análise conceitual elaborada, este artesanato mental em que o pensamento abstrato se organiza em sistemas ou estruturas de conceitos, amplos e sofisticados, no esforço por "penetrar" e interpretar, com sentido logicamente consistente, a complexidade do real. Isso a academia se habilitou a fazer, em processo de crítica e justificativa. Idéias se demonstram e hipóteses se testam, freqüentemente como unidades de complexos lógicos mais amplos chamados teorias.

Do ponto de vista da metodologia do conhecimento, é justamente isso, que aqui se chama de análise conceitual elaborada, a contribuição maior da administração como ciência social aplicada. Ela é também seu elemento mais estável, considerando-se as diversas dimensões do fenômeno administrativo, e decorrentes opções metodológicas preferenciais, hoje em prática.

\section{Características e Estratégias de Dissertaçōes em Mestrados Profissionals}

A característica geral e básica dos mestrados profissionais é que contribuam diretamente para o processo decisório ou operacional da empresa. Se um trabalho construído em moldes próprios da academia corresponde à expectativa da empresa, mesmo quando esta o financia, ele é perfeitamente aceitável em mestrado profissional. 
Não é esta última situação, no entanto, que costuma acontecer. A finalidade da pesquisa, a situação do mestrando, seu background escolar e perspectivas profissionais, o tempo disponível e, finalmente, seu interesse, conduzem a características especiais, aqui chamadas "não-acadêmicas". Além disso, quanto mais a definição da dissertação surge de dentro da empresa, mais é verdade que, metodologicamente, "cada dissertação tem que ser uma dissertação". Tenta-se formular a seguir, a partir de reflexão do autor sobre sua experiência, alguns elementos e estratégias que melhor ajudam, tanto a orientação do mestrando quanto certas decisões ligadas à coordenação dos cursos.

\section{A Relevância da Contribuiçăo}

Postos, acima, na definição do trabalho científico, os limites da qualidade formal, a qual deve ser vista em função da discutibilidade e do reconhecimento social, avulta a questão da relevância do tema. Ela será julgada, sem dúvida, pelo corpo docente, sob diversos critérios relativos ao mundo da produção e da organização sob estudo. Mas deve sê-lo principalmente sob o critério da utilidade para a própria empresa, arbitrada por ela ou com ela negociada. O mestrado profissional é programa cooperativo de formação e pesquisa que só funciona bem se a academia estiver disposta a rever sua atitude em relação ao objeto de poder, o mestrando e seu produto. A academia não precisa abdicar de sua competência analítica e metodológica, mas aceitar que não lhe cabe a última palavra quanto à relevância do que está sendo feito. Não é difícil concluir daí quanto seriam de repensar-se os recursos de acompanhamento do trabalho (que hoje excluem a empresa interessada), e até a composição das bancas examinadoras!

O critério da relevância precede a opção sobre a forma da contribuição e é por isso que se julgam trabalhos acadêmicos aceitáveis, se a empresa se considera em condições de apreciá-los e usá-los diretamente em seu processo decisório. Sem dúvida, a dissertação nunca será como simples trabalho de consultoria de processo, porque a empresa terá seu timing, sua conjuntura política e funcional interna para importação de conhecimentos sistematizados. Além disso, a complexidade das análises e informações proporcionadas por uma dissertação provavelmente tornará esta mais conveniente e vantajosa para problemas de importância estratégica. Mas há que se considerar um espectro de utilidade para o processo decisório, dentro do qual o uso mais direto é critério de relevância.

\section{Um Problema Real da Organização}

A dissertação em mestrados profissionais é pesquisa de solução para um problema da empresa. Tal seria o primeiro e grande compromisso do mestrando e de seu orientador de estudos. 
A academia tem seus problemas: as grandes questões em moda, desafios de formulação e interpretação, temáticas que consolidam grupos e escolas. A escolha do problema nas dissertações acadêmicas é, muitas vezes, função da escolha que o mestrando faz do orientador. Este tem suas áreas de interesse. A inversão desse movimento, exigindo uma adaptação do orientador, esbarra em limitações práticas de competência específica deste. Um "especialista convidado", alguém possivelmente do próprio meio profissional, trará contribuições específicas e pontuais a um trabalho que, no seu conjunto, continuará sendo conduzido pelo orientador, supostamente dotado de competência metodológica - capaz de adaptála a uma dissertação não acadêmica - e certa familiaridade com o campo teórico envolvido no caso.

Uma contribuição direta para o meio profissional, como o é a dissertação de mestrados profissionais, exige mais tempo na etapa de identificação do problema. Não é algo simples e intuitivo. Espontaneamente, o orientador, acadêmico, tende a "traduzir" rapidamente para seu mundo teórico ou temático, o problema que o mestrando lhe traz. No entanto o desafio é chegar ao problema real, proposto geralmente por meio de um conjunto de sintomas, e não "fugir a ele" ("resolvê-lo" rápidamente), pois sua formulação, até por pessoal da empresa, supõe já uma interpretação. Por isso problema e "solução" se delinearão até certo ponto juntos, ao longo de um trabalho de "intuição global" e formulação teórica. A busca da "solução" exige convivência mais prolongada com o problema (o que inclui entrevistas, observação direta e reflexão) e, quase que em apoio, com a literatura, interpretações já elaboradas. A partir de certo momento de formulação, a "solução" entra sobre trilhos, principalmente à procura de sua forma e de sua confirmação.

\section{A Estrutura}

É pouco dizer que o produto de toda dissertação é conhecimento. Melhor é caracterizá-la como ação: alguém (o autor) tem algo para propor de forma estruturada e justificada. Não há maneira única de fazê-lo. Assim ocorre com toda a produção científica ordinária, e não se justifica levar muito longe a padronização exigida hoje dos "infantes" mestrandos, fetichisando-se a estrutura da monografia dissertatória e alguns elementos analíticos como "objetivos gerais e específicos", "pergunta de pesquisa", "hipótese", e outros.

A rigidez na formalização não conduz à autonomia intelectual, apenas prova que ela não existe. Mas não é de negar que a forma sempre encerra o conteúdo. No caso do mestrado, as estruturas e estratégias de dissertação têm função propedêutica. Ajudam a preservar a lógica da dissertação e seu objetivo de propor de maneira estruturada e justificada um produto de conhecimento. Em princípio, é do mestrando a liberdade em relação à estrutura e o risco em relação àquele objetivo. 
Com tal ressalva, a função propedêutica da estrutura pode incluir um capítulo introdutório como elemento natural de texto que tem consciência de sua unidade, de suas opções quanto a objeto, finalidade e limites, e relevância. Muitas vezes merece destaque especial na estrutura da dissertação a abordagem sistemática da origem e evolução do "problema" (como começou e a situação atual se formou). Os objetos da administração são históricos, se explicam principalmente pelo que aconteceu antes. Além disso, o trabalho de pesquisa precisa registrar seu próprio processo de elaboração, supostamente consciente. Assim, a metodologia, apresentada como unidade textual específica, representa formalmente o reconhecimento do critério científico da discutibilidade (ou "refutablidade", na linguagem de Popper para as ciências naturais). O trabalho científico é essencialmente "aberto" à análise e à crítica, no caso por uma banca examinadora. Enfim, se a dissertação tem algo para afirmar ou propor, após um trabalho analítico ou de investigação, deve reservar espaço para conclusões explícitas.

\section{“Fundamentação Teórica" ou "Contribuições Conceituais"}

A etapa do trabalho chamada de "revisão de literatura" para a "fundamentação teórica" é um dos fetiches mais terríveis para serem enfrentados pelo mestrando (fala-se aqui da sistematização teórica propriamente dita, não das informações descritivas e históricas específicas sobre o caso).

Ainda há professores e mestrandos que tratam o assunto como se da quantidade de material teórico dependesse o grau de cientificidade da dissertação. É freqüente que mestrandos não sabem exatamente o que procuram nas leituras nem até onde é preciso ler. Sem dúvida, pensam, conhecer a literatura mais ou menos relacionada com o assunto é sempre importante (afinal, lembram a fase de créditos em disciplinas). A grande questão, que muitas vezes fica sem resposta satisfatória, é a relação exata e não sobeja entre o material teórico reunido, até dezenas de páginas, e o que o precede ou segue. Supõe-se que "fundamenta" (o que, da dissertação?). Mesmo que haja uma relação meio distante com as precedentes definições da pesquisa, e muita coisa não seja usada a seguir, de qualquer forma, pensa o noviço, dá autoridade ao trabalho e "mostra conhecimento geral"... Faria parte do rito. Afinal, todo trabalho acreditado como científico não tem que citar e referenciar?

Por que isso é tão caro à academia? As ciências são tradições, estão entre os legados sociais de conhecimento. Longas e complexas cadeias de investigação pessoal e registro, suportadas por instituições. Este grande legado, de que a academia se considera guardiã, conserva-se e transmite-se por meio da literatura, das disciplinas, e há esforços para expressá-lo em manuais e sínteses do "estado da arte". A partir da história das ciências da natureza, Thomas Kuhn analisou os mecanismos de formação e consolidação da "ciência normal". Ela é essencialmente conservadora e mesmo defensiva em relação à dissidência. Ela se atém a 
seus paradigmas, como "leis" e verdades. As "revoluções científicas" só são reconhecidas a posteriori, depois que novas questões permanecem sem resposta da ciência tradicional por muito tempo, impondo-se então uma corrente de explicações julgadas sustentáveis, elas próprias em seguida revestindo as características de "nova" "ciência normal".

As dissertações acadêmicas se ordenam para a tradição. Dela partem e a ela retornam com alguma contribuição, desenvolvendo teorias, comprovando ou rejeitando, pela aplicação, sua viabilidade. Basicamente, a academia se autoalimenta. As dissertações em mestrados profissionais de administração não têm essa finalidade. Levam da tradição acadêmica para o mundo da ação algo específico: elementos de análise conceitual elaborada, definida em item anterior como a contribuição típica do trabalho acadêmico ao processo decisório da empresa. $O$ produto de conhecimento acadêmico não constitui a base do produto de conhecimento gerencial, mas elemento instrumental indispensável. Inspira e alimenta mais do que aumenta a probabilidade do acerto. Administração diz respeito à percepção de alguém e sua opção em situação. Pode haver dissertações científicas em administração sem base em teorias reconhecidas, embora, é claro, a situação contrária também possa acontecer. A contribuição de análises conceituais, mesmo originais, no entanto, é sempre indispensável, e a tradição científica põe à disposição um grande estoque.

É possível distinguir pelo menos duas situações. Em uma, o produto da dissertação e seu argumento ao longo dela necessitam de interpretação geral de fatos ou de modelo inspirador. O mestrando recorre então especificamente a uma (ou mais de uma) teoria, escolhida com ajuda de seu orientador, e aí ele terá sua "fundamentação" teórica, que pode até constituir um capítulo de sua dissertação. Em outra, não tomando uma teoria em seu conjunto como base de argumento, recolhe-se aqui e ali na tradição acadêmica, conceitos consistentes e já trabalhados, usando-os na "solução" para o problema em estudo; pode-se, então, falar de "contribuições conceituais específicas" usadas em diversas partes de sua dissertação. De qualquer forma, o essencial e indispensável da contribuição acadêmica não está tanto nos conteúdos, colhidos com propriedade da literatura, mas na prática da análise conceitual elaborada, em que os termos são trabalhados, definidos, articulados e justificados. Não há, pois, tempo a perder com longas "revisões de literatura", no final das quais se costumam sumariar, em seqüência, diversas opiniões correntes sobre o assunto.

\section{Tipos Básicos de Dissertação}

Além do que depende dos elementos acima, não há um conjunto de formas prédefinidas para o desenho ou estratégia de dissertação em mestrados profissionais. Um esforço de classificação, no entanto, pode ajudar a entender isso. 
a) As dissertações interpretativas. Elas proporcionam uma explicação de fatos ou situações externas ou internas à organização, dado o momento e o contexto desta. Aqui é possível se incorporarem estratégias acadêmicas de pesquisa, tendentes a interpretar a realidade exterior. A maneira de fazê-lo e o nível de generalidade da interpretação devem ser tais que o prosseguimento da solução rumo às decisões reais possa ser claro e conseqüente. Também é possível uma dissertação interpretativa, seguida já de conclusões e sugestões singulares para a ação administrativa, desde que restritas apenas à interpretação dada.

b) As dissertações projetivas. Constituem desenvolvimento e/ou aplicação de políticas, de estratégias, de modelos conceituais, de processos técnicos (de administração de recursos humanos, de marketing, de finanças, de sistemas de informação, de consultoria de mudança, e outros), sempre explicados com base em sua estrutura conceptual subjacente. Elas não comportam hipótese (no sentido do método acadêmico) nem são objeto de teste. Envolvem proposta, que é justificada internamente por sua consistência analítica e, externamente, pelo reconhecimento credenciado de seus elementos, bases e fontes, como qualquer dissertação.

c) As dissertações avaliativas. Trata-se de revisão e análise de resultados de programas, de projetos, de políticas, de estratégias e outros, já implantados em algum momento do passado da empresa. Elas supõem a explicitação da base conceitual da avaliação (enfoque, critérios, indicadores) e se justificam, além disso, pela consistência analítica e qualidade dos dados levantados.

\section{A Questão das Técnicas}

Entre dissertações em mestrado profissional e dissertações acadêmicas, o que diferencia as técnicas de levantamento e tratamento de informações não é propriamente a diversidade de natureza, mas o uso delas no desenho e objetivo prático do trabalho. Estes são o critério de utilização daquelas, que, geralmente, resultam modificadas: menos exigentes na apresentação formal e quando não se precisa atingir tanta variedade nem generalização no objeto; mais exigentes quando se precisa de informações mais específicas para o uso ou a decisão. O preciosismo fica, de entrada, excluído. Há que se notar o fato de que a maior parte dessas técnicas foram desenvolvidas em contexto positivista ou para ciências naturais, com preocupação obsessiva ou mal definida da objetividade.

De qualquer forma, grande arsenal de técnicas está à disposição para uso criterioso: de entrevistas e análise de documentos a levantamentos e testes estatísticos em banco de dados. Até as técnicas de "pesquisa participante", por exemplo, desenvolvidas nas décadas de 60 e 70, em pesquisas de objetivo sóciopolítico, 
podem ter aplicação em uma pesquisa-ação dentro da empresa. Como muitas das dissertações em mestrados profissionais são estudo de caso, o método etnográfico parece particularmente interessante. Enfim, a experiência acadêmica na identificação, no tratamento e registro cuidadoso de fontes é contribuição que deve deixar sua marca na dissertação.

\section{Conclusão: “Deseja-lo-Ão os ACAdÊmicos?”}

Este texto não estuda a viabilidade prática das dissertações não acadêmicas em mestrado profissional, sem dúvida um produto híbrido. Afirma-se aqui sua possibilidade e justificativa teórica. A viabilidade é questão política: os acadêmicos, especificamente os professores orientadores, estarão dispostos a repensar convicções? Aceitar a aprendizagem e as inseguranças de iniciar uma nova prática? Que iria motivá-los? Como olharão as dissertações, de que costumam sentir-se co-autores? "São dignas de mim?", "O que pensarão da minha capacidade acadêmica os meus pares, que continuarão julgando dissertações tradicionais?" Se os professores não chegarem às bases metodológicas que justificam dissertações não acadêmicas e podem dar-lhes foros de cidadania no mundo da ciência, nunca deixarão de achar que lhes falta a sofisticação formal e literária, cultuadas no meio deles. Não se disporão a fazer coisa diferente do que se faz hoje em seu meio. E como poderão interessar-se pelo que lhes parecerá "dissertações de segunda classe"?

A Portaria n. 47 da CAPES pode ter posto um desafio. Pois a questão das dissertações em mestrados profissionais trará outra no seu rastro: a da relevância social da academia.

\section{ReFERÉNCIAS BibLIOGRÁficAs}

BARCHELARD, G.

Conhecimento comum e conhecimento científico. In: Epistemologia: a teoria das ciências questionada por Barchelard, Miller, Canguilhem, Foucault. Rio de Janeiro: Tempo Brasileiro, 1972.

BARNES, B.

Interests and the growth of knowledge. London: Routledge and Kegan Paul, 1977.
BREDO, E.,

FEINBERG, W.

Knowledge and values in social and educational research. Philadelphia: Temple University Press, 1982.

DAHRENDORF, R.

Ensaios de teoria da sociedade. Rio de Janeiro: Zahar, 1974. 
DEMO, P.

Metodologia científica em ciências sociais. 2.ed. São Paulo: Atlas, 1989.

Pesquisa e construção do conhecimento. 2.ed. Rio de Janeiro: Tempo Brasileiro, 1996.

ECO, U.

Como se faz uma tese. São Paulo: Perspectiva, 1989.

GADAMER, H. G.

Truth and method. New York: Seabury Press, 1975.

\section{GEERTZ, C.}

The way we think now: the ethnography of modern thought. In: Local knowledge. New York: Basic Books, 1983.

\section{HABERMAS, J.}

Conhecimento e interesse. Rio de Janeiro: Zahar, 1982.

Conhecimento pós-metafísico. Rio de Janeiro: Tempo Brasileiro, 1990.

\section{KNORR-CETINA, K.}

The manufacture of knowlwdge: an essay on the constructivist and contextual nature of science. Oxford: Pergamon Press, 1981.

\section{KUHN, T.}

The structure of scientific revolutions. Chicago: University of Chicago Press, 1962.

LAKATOS, I.,

MUSGRAVE.

Criticism and the growth of knowledge. London: Cambridge University Press, 1970.

\section{LATOUR, B.}

Science in action: how to follow scientists and engineers through society. Cambridge: Harvard University Press, 1987.

\section{LINCOLN, Y.,}

GUBA, E.

Naturalistic inquiry. London: Sage, 1985.

\section{LYOTARD, J. F.}

The postmodern condition: a report on knowledge. Minneapolis: University of Minnesota Press, 1984.

\section{MAGEE, B.}

As idéias de Popper. São Paulo: Cultrix, [1975].

\section{MARTINS, G. de A.}

Metodologia de pesquisa em administração. In: XVII Encontro Anual da ANPAD, 1993, Salvador. Anais... Salvador: ANPAD, 1993, v.7, p.172178.

\section{POPPER, K.}

The logic of scientific discovery. London: Hutchinson, 1965.

Conjecturas e refutações. Brasília: UnB, 1972.

A sociedade aberta e seus inimigos. 2.v. São Paulo: EDUSP, 1974.

Replies to my critics. In: SCHILPP, P. (ed.). The philosophy of Karl Popper. La Salle: Open Court, 1974.

SANTOS, B. de S.

Introdução a uma ciência pós-moderna. Rio de Janeiro: Graal, 1989.

SHÖN, D.

The reflective practitioner. New York: Basic Books, 1983. 